\title{
Universidade Corporativa: (Pré-) tendência do Ensino Superior ou ameaça?
}

\author{
Marco Wandercil da Silva ${ }^{1} \&$ Newton César Balzan ${ }^{2}$
}

Recebido 27/8/06

Aprovado: 14/11/06

\begin{abstract}
Resumo: O presente artigo tem como objetivo desvelar algumas implicações ideológicas do recente fenômeno denominado Universidade Corporativa (UC) em relação à educação superior formal, tendo como cenário as transformações políticas, sociais e econômicas intrínsecas ao neoliberalismo. A expansão dessa modalidade de ensino, ao mesmo tempo que sinaliza a demanda por um novo modelo de educação, parece revelar, como será apresentado, um caráter subjacente de competição, uma vez que a UC procura atrair uma "clientela" de alunos, criando cursos exclusivamente voltados ao mercado de trabalho. Dessa forma, emerge um embate silencioso em que se contrapõem, de um lado, as empresas, por meio das UCs, e de outro, as universidades tradicionais. Nossa principal indagação, portanto, seria: como essa mesma universidade tradicional irá reagir diante das exigências e das mudanças decorrentes do ensino corporativo, visivelmente contraditórias se comparadas às suas próprias funções? Ponderamos que o conhecimento disseminado pelas UCs não contempla o ser humano em sua formação ampla, tratando-se apenas de mais uma estratégia lucrativa das organizações empresariais, por meio da qual se privilegia o termo 'universidade' ao invés de 'centro de treinamento' - designação esta que parece ser mais apropriada às UCs em questão nesta pesquisa - e banaliza-se o conhecimento, além de não levar em conta a formação, em cada trabalhador-aluno, da consciência de seu papel na sociedade.
\end{abstract}

Palavras-chave: Educação Superior, Universidade Corporativa, Mercado de Trabalho, Neoliberalismo.

Corporate University: (Pre)tendency of Higher Education or threat?

\begin{abstract}
The purpose of the present paper is to reveal some ideological implications of the recent phenomenon called Corporate University (CU) relating to the formal higher education, within a setting of political, social and economical transformations intrinsic to neoliberalism. The expansion of this modality of education indicates a demand for a new educational model and, at the same time, seems to reveal, as will be presented here, an underlying aspect of competition, since the $\mathrm{CU}$ wishes to attract to itself a "clientele" of students, creating programs exclusively dedicated to the labor market. Thus, emerges a silent battle in which are opposed, on one hand, the companies, through the CUs, and on the other hand, the traditional universities. Therefore, our main question would be: how will this traditional university react to the requirements and changes originated by corporative education, clearly contradictory to its own functions? We ponder that the knowledge spread by CUs does not contemplate the human being in a broader educational sense, and is but another lucrative strategy of the business organizations, in which the term "university" is privileged instead of "training center" - a designation that seems to be more appropriate to the CUs studied in this research - and the knowledge is trivialized, without taking into account, during the education of each worker-student, the awareness of his role in society.
\end{abstract}

Key words: Higher Education; Corporate University; Labor Market; Neo-liberalism.

\footnotetext{
${ }^{1}$ Mestre em Educação, Analista de Avaliação Institucional - PUC-Campinas, Prof. Assistente da Policamp (Faculdade Politécnica de Campinas) e Prof. Adjunto do IESA (Instituto de Ensino Superior de Americana).E-mail: wandercil@terra.com.br

${ }^{2}$ Pós-Doutorado - Boston University, USA; Prof. Titular da PUC-Campinas; Prof. Voluntário da Unicamp; Bolsista do CNPq Nível 1A. E-mail: nbalzan@uol.com.br
} 
A globalização de mercados e o alto desenvolvimento tecnológico vividos nas últimas décadas conduzem a constantes e significativas transformações que desafiam as pessoas físicas e jurídicas a se adaptarem a novos ambientes altamente competitivos, velozes e permeados por incertezas. Para que seja possível refletir sobre a educação hoje, é necessário, primeiramente, problematizar o neoliberalismo e suas características multifacetárias, sua retórica ideológica, suas estratégias flexíveis, inovadoras e em constantes oscilações, que pregam transformações econômicas, políticas, culturais e sociais, em nível mundial, mas com profundo impacto local. Esse cenário de exigências e leis de mercado servirá como pano de fundo para o presente artigo. Partindo dele, iremos discutir uma proposta alternativa de educação superior, segundo a qual o conhecimento tornou-se o fator de produção mais importante.

As Universidades Corporativas (UCs) correspondem a uma modalidade de ensino gerida por grandes corporações empresariais, para além dos portões das fábricas, cujo foco é totalmente voltado à educação corporativa $^{3}$, e que tem preocupado muitas instituições de ensino sobre suas reais influências na formação do trabalhador e no contexto educacional brasileiro. O conceito de aprendizagem organizacional, que fundamenta a educação corporativa, ganha cada vez mais espaço, deixando educadores e pesquisadores receosos frente à possibilidade de as universidades corporativas assumirem um papel dentro do contexto do Ensino Superior para o qual, segundo nos parece, não se mostram preparadas.

O nosso objetivo é justamente elucidar o fenômeno de difusão do conhecimento nas organizações empresariais, por meio das UCs, atentando para as políticas neoliberais ${ }^{4}$, que desencadeiam um processo de aculturamento e consumismo desenfreado, refletido, infelizmente, na educação, tornada produto, para que possa garantir melhores resultados às empresas. Consequientemente, as universidades tradicionais perdem sua hegemonia, com impactos na educação e na sociedade.

As organizações empresariais, movidas pela concorrência sem limites, exigem dos trabalhadores uma nova postura. Suas atividades funcionais não podem mais se restringir à simples repetição mecânica. Hoje, os profissionais almejados por essas corporações necessitam estar capacitados para um considerável número de competências operacionais, somadas a outras tantas habilidades comportamentais. Para tanto, foram instituídos

\footnotetext{
${ }^{3}$ Neste trabalho, Universidade Corporativa e Educação Corporativa terão o mesmo significado e doravante serão denominadas UC e EC, respectivamente.

${ }^{4}$ Para melhor entendimento do termo "políticas neoliberais" ou "neoliberalismo" e suas conseqüências na sociedade, cf. http://educaterra.com.br/voltaire/atualidade/neoliberalismo.htm. Acesso em: 13 mar. 2005; Anderson (1995); Santomé, (2003).
} 
espaços específicos para o desenvolvimento dessas competências (ainda que seja difícil estabelecer um arquétipo ideal de profissional) - as mencionadas Universidades Corporativas.

A expressão "Universidade Corporativa" foi criada na década de 1980, nos Estados Unidos, com o aparecimento das primeiras instituições de ensino desenvolvidas por empresas privadas, para complementar a formação profissional de seus funcionários. Apesar de não serem tão recentes, somente a partir dos anos 90 do século passado é que as UCs estabeleceram-se como alternativa no Brasil, conquistaram e adquiriram dezenas de empresas adeptas a essa modalidade de ensino.

Inúmeros projetos de UCs têm sido implantados no Brasil por grandes empresas, que transferem para a EC o sucesso de seus modelos empresariais de serviço e a acessibilidade à tecnologia avançada. Assim, a educação superior se torna, cada vez mais, única e exclusivamente voltada ao mercado. À primeira vista, essas soluções educacionais parecem bastante positivas, no sentido de beneficiarem todos os envolvidos. Entretanto, constatamos que essas UCs desenvolvem suas atividades para viabilizar os conhecimentos requeridos pelo setor produtivo da empresa, excluindo qualquer tipo de disciplina que possa abranger uma formação mais humanística, que forneça ao aluno condições de análises e leituras políticas e sociais.

Para melhor compreender as mudanças políticas, sociais, econômicas e o processo de globalização de mercados, Dias Sobrinho (2005, p. 164) faz uma reflexão muito importante sobre o sistema universitário inserido nesse cenário, afirmando que:

Nada em nosso tempo pode ser pensado sem que se levem em conta as características atuais da globalização. Tendo em vista que os esquemas simples de compreensão da realidade social são insuficientes para dar conta da complexidade e da pluralidade de sentidos dos fenômenos humanos, especialmente com a fragmentação e a multiplicação dos conhecimentos, das informações e dos intercâmbios, já não se pode pensar que uma instituição central da sociedade, radicalmente ligada às mudanças do mundo, como é o caso da universidade, possa ser explicada a partir de uma única idéia ou de um só princípio interno.

Todo esse processo tem gerado profundas transformações na sociedade contemporânea, até mesmo na cultura, fortemente marcada pelos meios de comunicação. Dessa forma, a cultura local, o Estado, o mundo do trabalho e a educação acabam por sofrer influências neoliberais, sendo forçados a se adequarem a um modelo pseudo-autônomo, uma falsa sensa- 
ção de autonomia e liberdade: o conhecimento na era da globalização tem sido utilizado na prática mais para inovar as condições de lucro do que para humanizar as condições de trabalho e promover a autonomia do indivíduo.

Apostar na formação do cidadão dentro de uma universidade que depende de políticas monetárias e investimentos internacionais é o mesmo que restringir o saber ao conhecimento instrumental, necessário à competitividade de mercado. Cada vez mais se tem fortalecido o discurso das competências e da qualidade total ${ }^{5}$.

Como nossa discussão a respeito da universidade constrói-se num contexto de globalização de mercados, surge a questão: qual é o papel dessa instituição na formação do profissional e de quem é cobrada uma postura extremamente arrojada e de decisões imediatas? Com relação a esse questionamento, Dias Sobrinho (2005, p. 164-165) afirma que "a globalização exerce hoje pesadas pressões, a maioria delas marcada pelos sinais da urgência e das contradições. As universidades sofrem pressões contraditórias num cenário de turbulências e encruzilhadas, para o qual não se sentem preparadas a responder."

Além das pressões, as universidades passam por um momento de profundas transformações decorrentes das políticas neoliberais, quando procuram se re-adequar e trilhar uma nova trajetória. O impacto da globalização tem feito com que o papel dessas universidades seja constantemente repensado, visto que o mercado espera delas uma postura mecânica de "fabricar mão-de-obra" para atender às suas necessidades.

Apesar do ensino universitário ter assumido um caráter eminentemente técnico nas últimas décadas, a constante mutação dos perfis profissionais tem provocado um movimento de recuperação do valor da educação geral e da formação cultural do tipo humanista, de modo a desenvolver nos estudantes criticidade, criatividade, raciocínio lógico, iniciativa para resolução de problemas, capacidade de trabalhar em equipe. Buscase um profissional mais flexível, menos ocupado com o conhecimento técnico que com a capacidade de aprender. (MENEGHEL, 2001, p. 251).

Essas características que o mercado passou a exigir do profissional são limitadas. Quando analisadas no campo da operacionalização de tra-

\footnotetext{
${ }^{5}$ Segundo o European Foundation for Quality Management (EFQM), a qualidade total (TQM Total Quality Management) é caracterizada pelos seguintes fatores: excelência nos processos; cultura de melhoria contínua; criação de um melhor relacionamento com os clientes e fornecedores; envolvimento de todos os trabalhadores; e clara orientação para o mercado. Os melhores exemplos da aplicação da gestão da qualidade total são as empresas japonesas, que, ironicamente foram ensinadas, nos anos 40 e 50, pelos mestres americanos Deming e Juran. CF: Dicionário de RH (2003, p. 113-115).
} 
balhos técnicos, observamos que o profissional tem de dispor das seguintes qualidades: estar atento a todas as transformações resultantes do processo de globalização; manter uma 'postura crítica' quando um colega de trabalho não está cumprindo com o seu papel no processo de produção; 'ser flexível', porém nos limites de sua célula de trabalho; 'ter iniciativa para resolver problemas', na maioria das vezes, da máquina, e não os seus; 'trabalhar em equipe' para melhorar a produtividade, e não para criar laços de coletividade. Enfim, esse profissional tem que ser um 'multi-profissional polivalente' para atender às necessidades do mercado, enquanto suas necessidades pessoais não são satisfeitas.

Por não conseguir atender às demandas de um mercado altamente exigente e carente de profissionais capacitados para lidar com constantes metamorfoses da tecnologia, a universidade enfrenta um momento em que sua tarefa de formação e preparação do homem é assumida pelas UCs.

Entretanto, esse sistema consome-se em suas próprias contradições, pois, se o discurso neoliberal insiste no papel estratégico da educação para a preparação da mão-de-obra para o mercado, ele também se torna hegemônico num momento em que a revolução tecnológica impõe o desemprego estrutural, sem oferecer ao cidadão alternativas de sobrevivência fora do processo.

O modelo empresarial de gestão por competência teve sua origem nas teorias organizacionais clássica e científica, incorporando e se remodelando por meio das teorias mais recentes de gestão. Esse desenvolvimento pode ser claramente denominado por 'darwinismo gerencial', pois consiste em constantes adaptações, para uma melhor eficácia, uma vez que as estratégias da gestão estão voltadas para o máximo de produtividade, na produção em série e na economia de escala.

O modelo de universidade que temos hoje é o de uma instituição fundamentada no paradigma da ciência positivista, com disciplinas isoladas e conteúdo fragmentado. Sua estrutura administrativa é recalcada pelo 'peso' da máquina burocrática e seu aparelhamento baseia-se no modelo Taylorista $^{6}$ de organização da produção, o qual, no ambiente escolar, faz do professor um técnico 'treinado' para o manejo da classe, excluindo-o da função de pensar e planejar a ação educativa na sua totalidade.

Esse modelo foi instaurado na educação por meio da privatização do ensino em larga escala, que urgia por profissionalização nos sistemas de gestão das Instituições de Ensino Superior - IES. O principal aspecto é a

\footnotetext{
${ }^{6} \mathrm{O}$ método Taylorista, definido como "a aplicação de métodos científicos para o problema de obter eficiência máxima em trabalho industrial ou outros”, foi aplicado indiscriminadamente no início do século passado para aumentar a produção nas fábricas, sempre à custa do trabalhador.
} 
adequação da universidade aos mecanismos capitalistas, de modo que elas funcionem à semelhança do mercado. Nesse quadro, fazer da universidade um veículo de transmissão da ideologia significa enquadrá-la na reprodução eficaz dessa ideologia ${ }^{7}$.

$\mathrm{O}$ fato de o neoliberalismo apresentar-se como ideologia progressista, lado a lado com o processo de globalização e de internacionalização da economia e confiante de que o mercado se auto-regula, não significa que não haja problemas sociais, políticos e econômicos. No discurso neoliberal, a educação deixou de ser parte do campo social e político, para ser parte do mercado e funcionar à sua semelhança.

Quando falamos em educação e seus sistemas, percebemos uma grande quantidade de conceitos emprestados do âmbito da economia de mercado. Esses conceitos podem ser assim evidenciados:

Currículos ou matérias profissionalizantes; orientação profissional; habilidades formativas; produtos ou desempenho; privatização; gerenciamento; mercado; clientes; competitividade; reestruturação; eficiência; excelência; flexibilidade organizativa; capital humano; padrões; desregulamentação... Nos discursos que mais circulam ultimamente, os estudantes e suas famílias são apresentados como clientes, e, assim, os professores e professoras se transformam em 'produtores', e os currículos, 'produtos ou bens de consumo'. (SANTOMÉ, 2003, p. 221)

O Ensino Superior tem sofrido diversas pressões por parte do mercado para se estabelecer como canal de disseminação da ideologia neoliberal por meio dos conceitos de competências.

Nos tradicionais processos de recrutamento e seleção, novos instrumentos, novas técnicas vêm sendo empregados, visando identificar pessoas com potencial de crescimento, flexibilidade para enfrentar incidentes críticos e as novas demandas da empresa, pensamento estratégico. Os processos de treinamento e desenvolvimento assumem novos contornos, criando-se, inclusive em algumas empresas o conceito de Universidade Corporativa; o ponto chave desse conceito é

\footnotetext{
${ }^{7}$ Ideologia é um conjunto lógico, sistemático e coerente de representações (idéias e valores) e de normas ou regras (de conduta) que indicam e prescrevem aos membros da sociedade o que devem pensar e como devem pensar, o que devem valorizar e como devem valorizar, o que devem sentir e como devem sentir, o que devem fazer e como devem fazer [...]. A função da ideologia é a de apagar as diferenças, como as de classes e de fornecer aos membros da sociedade o sentimento da identidade social, encontrando certos referenciais identificadores de todos e para todos, como por exemplo, a Humanidade, a Liberdade, a Igualdade, a Nação, ou o Estado. (CHAUÍ, 1980, p. 113).
} 
que todo o processo de desenvolvimento das pessoas deve estar alinhado à definição das estratégias de negócio e competências essenciais da organização. (FLEURY; FLEURY, 2001, p. 65)

Não basta ao universitário ter apenas habilidades técnicas e/ou comportamentais, é preciso estar qualificado para o mercado. O discurso sobre a educação, cujo referencial foi totalmente incorporado do neoliberalismo, se tornou clichê.

O neoliberalismo afina-se com qualquer regime político que assegure os direitos à propriedade privada. O que importa é neutralizar os movimentos sociais e os guetos de resistências, como a educação. No neoliberalismo, o mercado é quem tudo regula, faz os preços subirem ou baixarem, estimula a produção, elimina o "incompetente" e premia o sagaz e o empreendedor. Metaforicamente, ele é o "deus" da economia moderna, tudo vê e tudo ouve e é ele quem fixa as leis e o curso que elas devem seguir.

Essa ideologia dominante suprime o direito a uma educação libertadora $^{8}$, enquanto enfatiza cada vez mais as diretrizes do mercado ávido por consumidores. Como há ausência das liberdades públicas e democráticas, ocorre regressão no campo social e político, no qual o cidadão trabalhador se reduz a um mero "consumidor".

Nesse contexto, as universidades, sem alternativa, adaptam-se às necessidades do mercado, a fim de formar mão-de-obra qualificada, visando atendê-lo. E o papel da universidade se redefine:

Neoliberal porque se orienta não mais para as necessidades da nação, mas para as exigências do mercado; porque se vê como um empreendimento como tantos outros, sendo preferível que sua iniciativa seja privada, não pública; porque sua administração deve atender antes aos requisitos da eficiência gerencial do que aos reclamos da participação política; porque não se vê mais como uma instituição que tem um compromisso para melhorar a vida social, deixando questões como essa ao livre jogo das forças do mercado; e, enfim, neoliberal, porque passa a se definir como um espaço onde o indivíduo busca instrumentos para o seu sucesso na sociedade e não onde a sociedade habilita indivíduos para seu serviço. (CASTANHO, 2000, p. 36).

\footnotetext{
${ }_{8}^{8}$ Paulo Freire, em seu livro Educação como prática da liberdade (1967), explica que, numa ação educativa libertadora, existe uma relação de troca horizontal entre educador e educando, exigindose nesta troca atitude de transformação da realidade conhecida. É por isso que a educação libertadora é, acima de tudo, uma educação conscientizadora, na medida em que, além de conhecer a realidade, busca transformá-la, ou seja, tanto o educador quanto o educando aprofundam seus conhecimentos em torno do mesmo objeto cognoscível, para poder intervir sobre ele.
} 
Uma das estratégias para perpetuar as doutrinas neoliberais é utilizar-se de todos os mecanismos possíveis de massificação e proliferação da ideologia dominante. Diante disso, Santomé (2003, p. 45) afirma que "para isso, (o mercado) tentará buscar apoios sociais que colaborem na busca do consentimento dos profissionais da educação e na formação do senso comum em toda a população, para que o sistema educacional trabalhe de forma mais eficiente."

A ideologia na sociedade capitalista pressupõe a elaboração de um discurso homogêneo e pretensamente universal, que busca identificar a realidade social com os anseios e interesses da classe dominante, ocultando as contradições existentes e silenciando as representações contrárias.

Quando falamos em ideologia, discorremos sobre as políticas neoliberais, incorporadas ao universo acadêmico. A busca pela melhora dos processos educacionais, por exemplo, é denominada qualidade total, um conceito ideológico já citado neste trabalho. A administração escolar, de acordo com essa ideologia, não seria responsável pela qualidade dos serviços prestados aos alunos, pelas condições de trabalho do docente ou pela disponibilização de recursos pedagógicos; ao contrário, o conceito de qualidade total adquire seu significado com base nas teorias administrativas da produção de bens de consumo, sem levar em consideração as práticas pedagógicas, o conteúdo curricular e as atividades docentes. Diante disso, Santomé (2003, p. 60) afirma que "a introdução de terminologias mercantilistas como 'excelência' e 'competitividade' serve (apenas) para gerar uma sociedade hiperindividualista, onde cada pessoa considera os demais seres humanos como rivais."

Tendo o sistema educacional se transformado assim drasticamente, observamos que o ensino superior já não é mais o único espaço de formação para o mercado. As últimas décadas têm sido marcadas pelo surgimento de empresas que formam o seu corpo funcional nas UCs, por meio dos processos de EC, isto é, a EC é uma estratégia das organizações para preparar seus recursos humanos de forma que possam se constituir em uma vantagem competitiva. O desafio é mantê-los sistematicamente atualizados em suas competências primárias, que dizem respeito a seus cargos, e a algumas competências básicas para os negócios da empresa.

Hoje, para executar quaisquer atividades, sejam elas técnicas ou administrativas, é exigida dos profissionais uma formação acadêmica superior, sólida fluência em mais de um idioma estrangeiro e experiência de trabalho na profissão, que, mesmo assim, não garantem uma boa colocação no mercado de trabalho. É a chamada lei da oferta e da procura ${ }^{9}$.

\footnotetext{
${ }^{9}$ Conceito da área de economia. De acordo com Antônio Corrêa de Lacerda, (2003) Prof. da Facul-
} 
Pressionados por essas exigências, os profissionais se vêem obrigados a buscar um diploma que lhes garanta, no mínimo, condições de competir num mercado de trabalho tão concorrido e cruel, em que predomina a necessidade aguda de formação de consumidores. Assim, a educação é também mais um produto de consumo, como os produtos da indústria cultural, da informática e bens de consumo (eletro-eletrônicos, vestuário, entre outros).

Isso revela o quanto a educação é tida como investimento financeiro especulativo, pois oferece aos seus investidores um retorno altamente positivo. Nesse contexto, a educação espera um comprador, como se fosse um simples artefato doméstico que se adquire em uma loja qualquer. O discurso que tenta justificar as mudanças sócio-econômicas não deve servir de argumento explicativo de todas as exigências do mercado. É necessário analisar criticamente todos os processos que envolvem a educação superior e as mais diversas formas de alienação utilizadas pelas universidades, já "contaminadas" pelo neoliberalismo e sua cultura de produção e de consumo.

Diante desse panorama, a sociedade corre o risco de ver as instituições de ensino como valiosas e necessárias apenas na medida em que oferecem uma formação adequada a esse novo mercado, para obter um posto de trabalho no setor privado. Dessa maneira, certas instituições de caráter público e, portanto, com interesses públicos, como as de ensino, são sugadas por serviços privados, transformadas em apêndices de empresas para as quais preparam gratuitamente mão-de-obra. (SANTOMÉ, 2003, p. 32)

Na mercantilização do sistema educacional, nas universidades e nos estabelecimentos de cursos superiores vocacionais, a linguagem da educação foi amplamente substituída pela linguagem do mercado, segundo a qual os professores universitários "entregam o produto", "operacionalizam a entrega" e "facilitam o aprendizado dos clientes", dentro de um regime de "gestão da qualidade", em que os estudantes transformam-se em fregueses, e selecionam módulos de aprendizagem ao acaso, em que "o desenvolvimento da habilidade técnica" ganha importância em detrimento do desenvolvimento do pensamento crítico.

Nessa perspectiva, analisamos de forma mais aprofundada os aspectos teóricos e acadêmicos de alguns argumentos do discurso neoliberal e 
verificamos algumas de suas falhas. Dentre elas, destaca-se o conceito sobre o papel do Estado e do mercado na educação, que revela a tentativa de tornar compatível a privatização do ensino e a educação de qualidade. Mas, a educação não é uma mercadoria para ser comprada e vendida. Podese comprar os meios para a educação, mas não o aprendizado em si.

O modelo de UC no discurso empresarial é visto como fonte de vantagem competitiva e de criação de um ambiente de aprendizado permanente. Para melhor compreensão desse novo paradigma educacional, voltamos às teorias de gestão, criadas por Taylor no início do século XX, que marcaram o apogeu da era industrial.

Seus princípios defendiam o paradigma mecanicista da empresa como máquina e das pessoas como engrenagens. Nesse período, a disponibilidade de mecanismos de enfraquecimento das reações dos trabalhadores não era tão ampla, limitava-se a poucas experiências de psicologia industrial então correntes. As tarefas eram repetitivas, a força de trabalho era relativamente homogênea, com cada funcionário atuando em funções préestabelecidas, sob uma liderança autoritária. A eficiência era o lema já que o treinamento dos funcionários habituava-os tecnicamente, diminuindo seus erros e aumentando sua produtividade e sua eficácia nos processos produtivos. Resultado: trabalhadores alienados aos métodos de produção.

As idéias de Taylor encontraram muita repercussão, por meio de sua obra e sua metodologia, atraindo inúmeros seguidores, entre eles, Henry Ford. Taylor concebeu a utilização do cronômetro como forma de fazer os trabalhadores executarem suas tarefas o mais rápido possível; Ford, por sua vez, inovou com sua esteira transportadora que unia os cantos da fábrica, para que todo o conjunto efetuasse suas tarefas de forma mais rápida.

A história do trabalho, no último século, revela o estabelecimento do taylorismo multifacetário, concretizado pela produção e reprodução das atividades produtivas, embora travestido e incorporado aos modismos de gestão e educação para o trabalho (treinamento), embelezado como algo novo e arrojado em termos de administração.

Karl Marx, em seu clássico "O Capital”, afirmava que, para a extração da mais-valia, era necessário diminuir o tempo de trabalho pago e, conseqüentemente, aumentar o tempo de trabalho não-pago ao assalariado. Leo Huberman (1972, p. 232-233), fundamentado em Marx define a mais-valia afirmando que

O sistema capitalista se ocupa da produção de artigos para a venda, isto é, de mercadorias. O valor de uma mercadoria é determinado pelo tempo de trabalho socialmente encerrado na sua produção. $\mathrm{O}$ 
trabalhador não possui os meios de produção (terras, ferramentas, fábricas etc.), que pertencem ao capitalista. $\mathrm{O}$ valor de sua força de trabalho, como o de qualquer mercadoria, é o total necessário à sua reprodução - no caso, a soma necessária para mantê-lo vivo. Os salários que lhe são pagos, portanto, serão iguais ao necessário à sua manutenção Mas, esse total que recebe, o trabalhador pode produzir em parte de um dia de trabalho. Isso significa que apenas parte do dia de trabalho o trabalhador estará trabalhando para si. O resto do dia, ele está trabalhando para o patrão. A diferença entre o que o trabalhador recebe de salário e o valor da mercadoria que produz é a maisvalia. A mais-valia fica com o empregador - o dono dos meios de produção. É a fonte do lucro, dos juros, das rendas - a renda das classes que são proprietárias. A mais-valia é também a medida da exploração do trabalhador no sistema capitalista.

Num estudo mais aprofundado sobre Taylor, percebemos que este incorporou as teorias de Marx, só que por um outro viés, uma vez que Marx analisava a luta de classes sob a ótica do proletariado, e Taylor desenvolveu toda sua teoria do ponto de vista do capitalista. No que diz respeito às atividades humanas, sem dúvida alguma os escritos de Taylor constituíram o primeiro "manifesto revolucionário" sobre o redesenho de processos de trabalho, visando aumentos radicais de produtividade.

Mesmo com toda carga de rejeição que o paradigma taylorista inspira até os dias de hoje, não se conseguiu substituí-lo completamente por enquanto, talvez porque não haja nenhum interesse por parte do capital para fazer uma radical ruptura, já que o taylorismo, em sua essência, ainda gera bons resultados, e, para superá-lo, seriam necessárias algumas ferramentas. No entanto, vários modismos 'revolucionários' já se constituíram. Desde os últimos vinte anos do século $\mathrm{XX}$, com a promessa de promover mudanças radicais nas performances das empresas, foram experimentadas da qualidade total à reengenharia de processos; da empresa voltada para o cliente aos times multifuncionais; da gestão por competência à Universidade Corporativa. Isso revela que, desde Taylor, os sucessivos modismos nos processos administrativos perpassam por todos os setores da sociedade, desde uma montadora de automóveis até uma universidade.

Uma boa maneira para compreender essa evolução é remeter à esteira de Ford até encontrar o modelo atual japonês conhecido como "toyotismo"10. Antunes enfatiza que não se pode atribuir ao toyotismo um cará-

${ }^{10} \mathrm{O}$ toyotismo é um novo modo de organização da produção capitalista, que surgiu no Japão na década de 50, mas somente a partir da crise capitalista dos anos 70 começou a ser "traduzido" 
ter de novo modelo de organização e de produção, nem ao menos é possível considerá-lo como um avanço do sistema taylorista/fordista, pois com ele foram implantadas singelas modificações no sistema de distribuição.

[...] a questão que nos parece mais pertinente é aquela que interroga em que medida a produção capitalista realizada pelo modelo toyotista se diferencia essencialmente ou não das várias formas existentes de fordismo. [...] a diminuição entre elaboração e execução, entre concepção e produção, que constantemente se atribui ao toyotismo, só é possível porque se realiza no universo estrito e rigorosamente concebido do sistema produtor de mercadorias, do processo de criação e valorização do capital. (ANTUNES, 1999, p. 33)

O sucesso do modelo japonês, entretanto, foi muito mais tributário de Taylor do que possa parecer, pois, a princípio, esse modelo coloca o cliente "em primeiro lugar", porém, quando se faz uma leitura mais apurada de seus conceitos, percebe-se nas entrelinhas da afirmação outros sentimentos. O modelo flexível japonês, no seu primeiro momento, esteve muito vinculado, na verdade, a sistemas otimizados de produção (alta qualidade com baixo custo).

Acreditamos que esse "modelo", portanto, não diverge dos pressupostos de Taylor. O 'cliente em primeiro lugar', não pessoas comprando produtos em primeiro lugar, produtos bons e baratos, devido ao sistema de produção. Após essa breve análise, concluímos que o toyotismo representou verdadeiramente uma ofensiva contra os trabalhadores, ainda que tenha se instalado como um processo apenas preocupado em resgatar o domínio e o poder de acumulação do capital. Taylor continua mais vivo do que nunca.

Outro modismo que contribui para nossa discussão é o "planejamento estratégico", também essencialmente taylorista adotado em muitas empresas e, inclusive, nas universidades, por orientação do MEC. Trata-se de um antigo processo em que se usava a inteligência para coletar, processar e interpretar a informação e, em seguida, definir os caminhos da empresa. Mas, essa inteligência não se desenvolve no "chão de fábrica", apesar de poder ser alimentada neste setor. Seu exercício continua um processo da elite hierárquica, que pensa pelos trabalhadores.

Pesquisas anuais da revista Exame para o guia "As melhores empresas para se trabalhar no Brasil" atestam que o trinômio treinamento-de- 
senvolvimento-educação adquiriu acentuado relevo em relação a outras práticas de Recursos Humanos. É surpreendente a quantidade de empresas elencadas nas últimas edições desse guia, que têm um sistema diferenciado de desenvolvimento de pessoas inseridas no conceito de UCs.

Além de estarem presentes em diferentes setores, as UCs são tão variadas quanto as organizações às quais estão vinculadas, assumindo diferentes características e se multiplicando vertiginosamente ano a ano. Apesar de ainda não ter a tradição de Educação Corporativa encontrada em países como os Estados Unidos, o Brasil já caminha para a implantação de uma cultura de formação de pessoas, extrapolando as paredes dos tradicionais departamentos de treinamento e desenvolvimento.

Segundo Eboli (2002), vale lembrar que o treinamento oferecido pelos antigos centros de Treinamento e Desenvolvimento das empresas era orientado na busca de soluções para casos pontuais, que envolviam a atualização de métodos e processos com foco nos indivíduos. Por sua vez, os papéis das UCs são orientados às tendências dos negócios, à qualificação tanto técnica quanto profissional de seus colaboradores, à promoção da educação permanente e às múltiplas alternativas de aprendizagem. Essas características não estão apenas alinhadas à estratégia organizacional e ao desenvolvimento dos funcionários, mas também a outros elementos da cadeia de valores da empresa, como clientes, fornecedores, distribuidores e parceiros.

Em seminário ocorrido a 5 de novembro de 2003 na sede da Associação Brasileira de Mantenedoras de Ensino Superior (ABMES) sobre Educação Corporativa como prática educacional inovadora, Alperstedt ${ }^{11}$ afirmou que a Educação Corporativa difere de um departamento de Treinamento e Desenvolvimento, porque atua com uma visão mais ampla e estratégica, adianta-se a determinadas questões, vincula-se aos negócios da empresa e atende aos diferentes níveis organizacionais. E dessa forma, a Educação Corporativa, no âmbito da empresa, promove o incremento da produtividade e lucratividade e prepara seus profissionais para atividades de gestão, voltadas às necessidades de mercado.

Muito embora a educação não seja o foco de uma empresa, a alternativa apresentada através das UCs seria a possibilidade de associação entre empresa e uma ou mais IES. Esta associação, porém, deveria ser feita com bastante cuidado e cautela, pois os objetivos específicos e as funções das instituições envolvidas são completamente diversos, gerando conflitos. O estabelecimento desses conflitos indica a necessidade de uma reflexão mais aprofundada sobre algumas tendências no ensino superior:

${ }^{11}$ Cristiane Alperstedt, Diretora da Escola de Negócios da Universidade Anhembi Morumbi. 
Há um entendimento da coisa técnica que me parece equivocado no trabalho do Ministério da Educação. [...] É a valorização da técnica em si e não do fenômeno técnico. Isso conduz a dar ênfase ao treinamento, que não é educação. O treinamento consiste em preparar rapidamente a mão-de-obra para tarefas que às vezes deixam de ter razão de ser, enquanto que a educação é algo que instrumentaliza o homem para ser mais e melhor cidadão, para entender mais e melhor o mundo, para se tornar um ser humano na sua plenitude. Nas condições atuais há uma insistência nesse aspecto instrumental da educação, em detrimento do aspecto propriamente formativo e isso se vê na proliferação de cursos noturnos, os cursos de correspondência, os telecursos, que são formas simplórias que podem enganar as pessoas durante algum tempo, mas não facilitam a incorporação a uma vida plena, que é o objetivo da educação. (SANTOS, 2001, p. A4)

Ao observar o ritmo das empresas e das universidades, Fredric Litto ${ }^{12}$ criticou: "as Universidades Corporativas surgiram porque não agüentaram o ritmo e a lentidão das universidades". No entanto, UC e Universidade Tradicional são duas entidades completamente diferentes, e uma não substitui a outra. Eboli (2002) afirma que a diferença está no aluno corporativo, que não é o jovem que quer ingressar no mercado de trabalho, mas sim o aluno que já ingressou, balizando, assim, a ênfase do ensino na prática das atividades. Ao falar que o foco são as atividades, entendemos que a UC simplesmente incorporou o setor de treinamento, dando-lhe uma nova roupagem e uma nomenclatura mais atraente, a fim de também incluir todos aqueles que gostariam de estar numa universidade tradicional.

Atualmente, as empresas têm disponibilizado altos investimentos no desenvolvimento da Educação Corporativa, leia-se, educação destinada ao trabalho e, para tanto, elas criaram o conceito de UC.

O uso da expressão "universidade corporativa" é reflexo da tradução livre da expressão recorrente na literatura americana: corporate university. O uso do termo "corporate" é decorrente do fato de que essas instituições estão atreladas a empresas, revelando que, pelo menos a princípio, a prestação de serviços educacionais não constitui per se o seu objetivo fundamental. Por sua vez, a adoção do termo "university" é justificada pelos empresários de diferentes formas.

\footnotetext{
${ }^{12}$ Coordenador Científico da Escola do Futuro da Universidade de São Paulo (USP), no seminário "Educação Corporativa como prática educacional inovadora", ocorrido em 05/11/2003, na sede da ABMES, Associação Brasileira de Mantenedoras de Ensino Superior, em Brasília.
} 
Todas, porém, voltadas para denotar uma seriedade de propósitos, em termos de comprometimento com os objetivos pretendidos. Meister (1999) destaca que também é arrolado, como justificativa para uso do termo, o objetivo de criação de uma marca para os seus programas educacionais, materiais didáticos e processos. Em casos extremos é usado como apelo mercadológico. (ALPERSTEDT, 2003,)

Evidentemente que o uso do termo "universidade" não confere a essas entidades a mesma conotação que a palavra possui no sistema educacional formal e o seu real significado no contexto do ensino superior.

Pode-se considerar que há uma competição subjacente quando pensamos que a UC traz ou retém para si uma parcela de "clientes" de cursos de especialização ou aperfeiçoamento oferecidos pelas Universidades. Como a certificação universitária pode significar um salário mais elevado devido à habilitação, não seria razoável pensar que a UC capacita seus funcionários sem esse ônus e para objetivos mais diretos? Para o funcionário essa capacitação interna oferecida pela empresa pode ser garantia de estabilidade no emprego, visto que há uma seleção / escolha de 'alunos' para cursar a UC; a Universidade Regular não garante, com a certificação, a empregabilidade e a estabilidade de ninguém.

A discussão sobre as UCs é recente, sendo incipiente o próprio conhecimento a respeito dessas instituições. Trata-se, então, de instituições nas quais ainda é necessário ampliar o conjunto de informações e reflexões através de uma discussão sobre este sistema 'educacional' paralelo.

Muitas são as razões para uma organização empresarial apostar na implementação de uma UC, dentre elas, criar um diferencial no desenvolvimento de seus funcionários, para atingir lucros altos em todos os componentes da cadeia de valor, ou seja, desenvolver seus trabalhadores, deixando-os mais aptos às atividades voltadas aos processos produtivos e sintonizando-os à cultura organizacional ${ }^{13}$.

Quando abordamos a questão das universidades corporativas, remetemo-nos a um termo implícito nesse conceito, o corporativismo ${ }^{14}$. Esta derivação esclarece os reais interesses a que respondem essas instituições, dentro de uma lógica capitalista que se perpetua como sistema absoluto. Analisando o capitalismo atual e suas políticas neoliberais, per-

\footnotetext{
${ }^{13}$ Cultura Organizacional - As empresas, tais como os países, não têm uma cultura única. É, por isso, crucial que divulguem explicitamente os seus valores,em documentos chamados "declaração de missão."

${ }^{14}$ Verbete do Minidicionário Ruth Rocha. (1996, p. 171 - 172) : 1. Sistema em que as classes produtoras se reúnem em corporações, sob a fiscalização de "alguém" e sujeita às mesmas regras e com os mesmos deveres ou direitos. 2. Associação que visa um fim comum.
} 
cebemos o quanto o discurso empresarial está impregnado dessa lógica, principalmente ao tratar de EC.

Antes das mudanças impostas pelo neoliberalismo globalizado, definido hoje como sistema capitalista flexível, o trabalho era para a vida toda. Mesmo sendo estafante e repetitivo, os trabalhadores podiam prever como seriam suas vidas. Contudo, com a flexibilização, o trabalhador tornou-se apto às mudanças, e, conseqüentemente, obrigado a encarar riscos. A insegurança e o medo da perda do controle amedrontam esse trabalhador, agora individualista, desconhecedor do senso de comunidade, o qual só sobrevive nas comunicações eletrônicas ${ }^{15}$, sempre breves, apressadas e sem consistência.

O cenário de individualização do trabalhador causado pelo capitalismo flexível exige que o indivíduo não se apegue ao que constrói, fortalecendo um traço de flexibilidade do caráter humano: a tolerância à fragmentação de suas atividades produtivas.

A tecnologia avança na reorganização e aprimoramento das formas de produção, redefinindo as condições de trabalho, pois o trabalhador necessita minimamente possuir conhecimentos básicos das novas tecnologias, para estar preparado e atualizado para as atividades produtivas. Vimos que, na teoria clássica de Taylor, o trabalhador vende sua força em troca de um salário. Em contrapartida, o trabalhador atual tende a vender não somente sua força de trabalho, mas também sua competência ${ }^{16}$, ou melhor, uma capacidade de aprender e inovar.

Acreditamos que a flexibilização nas relações de trabalho não só transferiu para os trabalhadores boa parte dos riscos empresariais como também os transformou em seus próprios carrascos. São eles, os trabalhadores, responsáveis pelos bons e maus resultados da exploração de sua própria força de trabalho e pelo recolhimento da mais-valia dela resultante. Todo esse discurso neoliberal da flexibilidade (de formas de contratação, de dispensa, de tempo, de local, de função) soa como pseudo-indício de ruptura com o paradigma da organização taylorista/fordista. Porém, é somente um modismo da área de administração, que recupera um modelo ainda não suplantado.

No desenvolvimento deste trabalho, procuramos entender a configuração das UCs, o cenário político-econômico em que estão inseridas, seu

\footnotetext{
${ }^{15}$ Para aprofundar o tema: Chaui (2003); Popper; Condry (1995); Saperas (1993); Breton (2002); Sites disponíveis na em: http://confrontos.no.sapo.pt; http://chip.cchla.ufpb.br/paraiwa/01dantasdasilva.html; http://resistir.info/; http://www.duplipensar.net

${ }^{16}$ Esse progressivo deslocamento conceitual da qualificação à competência tem sido amplamente discutido por diversos autores como: Hirata (1994); Deluiz (1996); Dubar (1998); Manfredi (1998); Ramos (2001).
} 
processo de implantação no Brasil, o discurso e o poder do capitalismo neoliberal sobre a educação, e especificamente, sobre essas entidades, ou seja, toda a lógica e a trajetória da universidade corporativa no Brasil.

O tema da criação das UCs é polêmico e ainda não muito estudado criticamente, porém, qualquer que seja a posição ideológica assumida diante desse tema, é inegável que o modismo gerencial, bem como as demais categorias de análise utilizadas pelas revistas especializadas na área de gestão, consideram o conceito de UC inovador, um diferencial competitivo. Essas instituições são claramente um fenômeno intrínseco à sociedade moderna de consumo, mas, a partir desse pressuposto, afirmar que elas solucionariam os problemas da educação nas empresas é um tanto quanto precipitado e extremamente limitado.

Não podemos deixar de mencionar que, a despeito de a universidade ainda ser o berço do conhecimento científico elaborado, ela se apresenta, hoje, de forma subserviente em relação ao capitalismo. A propósito, as palavras de Marilena Chauí, proferidas há um quarto de século continuam atuais:

A universidade tem hoje um papel que muitos não querem desempenhar, mas que é determinante para a existência da própria universidade: criar incompetentes sociais e políticos, realizar com a cultura o que a empresa realiza com o trabalho, isto é, parcelar, fragmentar, limitar o conhecimento e impedir o pensamento, de modo a bloquear toda a tentativa concreta de decisão, controle e participação, tanto no plano da produção material quanto no da produção intelectual. Se a universidade brasileira está em crise, é simplesmente porque a reforma do ensino inverteu seu sentido e finalidade - em lugar de criar elites dirigentes, está destinada a adestrar mão-de-obra dócil para um mercado sempre incerto. E ela própria não se sente bem treinada para isto, donde sua "crise". (CHAUI, 1980, p. 34)

Paralelamente a esses fatores, as UCs desempenham seu papel de complementar o ensino de graduação das universidades com treinamento e capacitação para o planejamento das organizações, como investimento necessário ao crescimento e à sobrevivência destas e à qualificação de seus colaboradores.

Uma universidade, segundo a Lei 9.394 /96, tem por finalidade promover o ensino, a pesquisa e a extensão, favorecendo o desenvolvimento das ciências em todos os ramos do conhecimento, das letras e artes, e permitindo uma formação de profissionais de nível universitário, apoiada em valores de transformação e comprometida com a extensão dos benefícios 
do desenvolvimento a todos os membros da comunidade. Definição que não é válida com relação à Universidade Corporativa. As empresas, como não são instituições de ensino reconhecidas por legislação, criam seus próprios ambientes de desenvolvimento de pessoas, em paralelo àquele legalmente definido pelo MEC. As UCs, por sua vez, possuem suas próprias regras, modificáveis de acordo com as necessidades e as estratégias de mercado de cada empresa.

Atualmente, os alunos que concluem seus cursos de graduação em instituições que ainda oferecem uma educação diferenciada estão "disponíveis" no mercado, disputando as poucas vagas que o mesmo oferece. E, mesmo assim, quando conseguem um emprego são contratados por salários inadequados, muito abaixo de suas expectativas e seus sonhos, criados durante o curso superior.

Como a grande maioria dos trabalhadores é oriunda de instituições incapazes de formá-los de maneira condizente com as exigências do mercado de trabalho, as empresas que precisam de mão-de-obra mais qualificada criam seus próprios centros de treinamento. As grandes empresas, então, desenvolvem a Educação Corporativa, embutidas nas Universidades Corporativas.

A complexidade no entendimento dos meandros subjacentes à discussão das IES com as UCs, está na intenção de perceber os caminhos para alternativas ao sistema educacional. Atualmente o acesso à educação tem-se democratizado por meio das leis de cotas, fator que interessa ao Estado que pactua com um mercado cada vez mais globalizado. A intenção do Estado é priorizar a formação superior da grande massa, mesmo sabendo que o "conhecimento aceitável", historicamente, está sob o poder de uma elite detentora do capital produtivo, dessa forma, cria-se um processo ideológico imposto por uma "pseudo-educação superior" que não agrega nada em relação à emancipação do cidadão trabalhador:

A ideologia da igualdade educacional revelou seus limites reais, pois a partir do momento em que a maioria adquiriu a possibilidade de receber os estudos superiores, estes perderam sua função seletiva e se separaram de seu eterno corolário. Isto é, a promoção social. Se todos podem cursar a universidade, a sociedade capitalista se vê forçada a repor, através de mecanismos administrativos e de mercado, os critérios de seleção. Isto implicou, [...] a desvalorização dos diplomas, o aviltamento do trabalho e dos salários dos universitários e finalmente, o desemprego. [...] Como consequiência, a universidade se mostrou incapaz de produzir uma cultura útil (não fornecendo, na 
realidade, nem emprego nem prestígio), incapaz de funcionalidade, tornando-se um peso morto para o Estado, que passou a limitar-lhe recursos. (CHAUI, 1980, p. 32)

Essa realidade, apontada por Marilena Chauí há 26 anos tornou-se um terreno fértil para o surgimento e a implantação das universidades corporativas nas empresas, uma vez que as formas de ensino, exclusivamente voltadas à formação profissional, confundem, muitas vezes, o próprio trabalhador que não consegue perceber que a ideologia imposta pelos cursos superiores tem conotações muito parecidas; que as regras que regem as políticas de ensino no país são as das cartilhas desenvolvidas pelo FMI, Banco Mundial, e outros órgãos, centrais para que seja definido o que é melhor para a formação superior, cuja direção é o atendimento das necessidades do capitalismo neoliberal.

A educação formal para o trabalho, em nível superior, começa a enfrentar uma concorrência inusitada de um segmento paralelo ao ensino formal: as UCs, surgidas com as experiências de programas de treinamento e desenvolvimento profissionais corporativos e com a constatação de que a universidade não tem conseguido preparar adequadamente seus alunos para o mercado de trabalho (embora esse não seja o papel exclusivo de uma universidade). Num cenário onde o capital e as políticas neoliberais impostas por órgãos internacionais conduzem os projetos voltados à educação, poucas são as alternativas da universidade que não adere ao sistema, pois não é possível manter-se à margem dele.

Atualmente, alguns intelectuais ainda mantêm o discurso em defesa do livre-arbítrio dentro dos espaços universitários, em prol da equalização social, da difusão de uma cultura ampla e do respeito às opiniões, ponto de vista que também compartilhamos, pois acreditamos numa universidade que cumpre o papel de transformação social sendo lócus do saber por meio da difusão do conhecimento e da liberdade acadêmica. Entretanto e infelizmente, as imposições políticas e econômicas apontam para uma universidade com características neoliberais voltadas ao imediatismo. A relação entre universidade e empresa, é assim explicitada por Santos (2004, p. 85):

Trata-se da relação entre a universidade e o setor capitalista privado enquanto consumidor destinatário de serviços prestados pela universidade. Como vimos, este setor surge hoje crescentemente como produtor de serviços educacionais e universitários. Aqui refiro-me a ele enquanto consumidor. A popularidade com que circulam hoje, sobretudo nos paises centrais, os conceitos de "sociedade do conhecimen- 
to" e de "economia baseada em conhecimento" é reveladora da pressão que tem sido exercida sobre a universidade para produzir o conhecimento necessário ao desenvolvimento tecnológico que torne possível os ganhos de produtividade e de competitividade das empresas.

Fica claro que esses componentes apresentados por Santos contribuem para o rápido crescimento das UCs, além de um outro fator, a necessidade de contínua aprendizagem, conseqüência das vertiginosas mudanças no mundo do trabalho, dos avanços tecnológicos permanentes e do processo de globalização da economia.

A educação está imersa no mundo dos negócios, envolvida em altas cifras pelo status e pelo poder. Embora as UCs constituam um bom exemplo, há, além delas, os chamados consórcios: grupos de empresas que preparam treinamentos aos funcionários, embasados em conteúdos adquiridos das IES e, depois, oferecidos no mercado aberto; universidades virtuais: são IES que oferecem cursos à distância em nível de graduação; e empresas de educação com fins lucrativos: um modelo empresarial cujo foco é oferecer uma educação voltada para profissionais que desejam obter um diploma, modelo este surgido e proliferado para atender o segmento de mercado e seus consumidores. A educação formal oferecida, atualmente, como mercadoria, transformou muitas instituições em empresas nas quais se paga pela obtenção de um serviço.

O mercado rotula o "tipo ideal" de profissional para atuar no cenário ambíguo que esse mesmo mercado criou. As empresas, por meio de suas UCs, capacitam seus colaboradores, a partir de necessidades, às vezes, contrárias a sua própria realidade. No entanto, o denominador - comum é justamente o arquétipo de profissional: competitivo, individualista, autônomo, criativo, enfim, possuidor de um arcabouço de competências e habilidades que o mercado exige. Paradoxalmente, esse mercado também requer pessoas que cumpram ordens, sejam disciplinadas, façam muitas tarefas sem questionar nem raciocinar. Assim, o "tipo ideal" de funcionário, quando adaptado ao mercado, torna-se um robô de fácil controle.

Verificamos que as maneiras e foco de atuação das UCs sobre o 'aluno' são novas facetas do taylorismo que primam, exclusivamente, pelos processos produtivos. Por mais que essas tentem mostrar que têm seu foco na extensão, um dos tripés do ensino universitário, seu olhar está voltado, apenas, à melhoria do campo de atuação profissional dentro da empresa.

Quando falamos de UC e do setor de treinamento, estamos falando da mesma coisa, na medida em que é possível implantar em qualquer empre- 
sa, através do próprio setor de treinamento, a "revolução" proposta por uma UC: basta uma administração coerente com investimentos necessários, sem precisar emprestar o nome "Universidade", uma vez que essas UCs não cumprem um papel tão amplo.

As UCs respondem às estratégias de marketing, pois vendem uma imagem para justificar os altos investimentos que a empresa tem como dispêndio na área de desenvolvimento profissional. A propósito, SILVA (2005) afirma que:

Todo o conhecimento nelas disseminado não contempla o ser humano em uma formação ampla, é apenas uma jogada do mundo corporativo. Ao final das contas, é muito mais 'glamuroso' ter uma 'universidade' que um 'centro de treinamento'. Acreditamos que as empresas, por meio das universidades corporativas, banalizam o saber, priorizam os "competentes", que já estão inseridos no interior de seus portões e possuem conhecimentos aquém das necessidades humanas e além de suas reais necessidades profissionais. Além do mais, tais UC não desenvolvem um trabalhador consciente de seu papel como cidadão na sociedade. (SILVA, 2005, p. 109)

A partir do exposto até aqui percebe-se que essa forma de educação empresarial não diverge da Teoria Clássica de Taylor, muito embora esteja mascarada e totalmente travestida, para ludibriar os trabalhadores numa retórica que mostra o velho como novo.

Numa universidade, a educação deve exercer o papel de possibilitar e desenvolver conhecimentos e valores, procurando trabalhar o homem em sua totalidade, englobando as dimensões técnicas, sociais, culturais e políticas. Tornando o homem apto não só para atender aos requisitos do mercado, mas sobretudo para atuar como cidadão consciente num mundo globalizado. A educação superior deve ser emancipadora, valorizar a autonomia, atender às necessidades da vida cotidiana e promover a formação intelectual e moral do ser humano, fornecendo-lhe condições para uma visão abrangente de mundo e capacidade de gerar novos modos de pensamento.

Ao contrário dos pressupostos sobre os quais se apóia a Universidade em seu sentido legítimo, as empresas vêm se utilizando do nome Universidade Corporativa apenas como um apelo mercadológico, levando-nos a concluir que a forma de atuação das mesmas é extremamente alienante, pois conduz o trabalhador a um "prazo de validade" dentro de uma organização e a uma ideologia passageira. Lutar pela empresa não é motivo de orgulho, é uma submissão temporária, pois a cada novo emprego, 
corresponde um novo estilo e formas de trabalhar, fator propiciado pelas variadas tecnologias e farta mão-de-obra disponível no mercado.

\section{Referências}

ABMES discute educação corporativa no contexto brasileiro. ABMES Notícias, Brasília, n. 81, out-dez, 2003. Disponível em: <http:// www.abmes.org.br/Publicacoes/Jornal/81/pag05.htm> Acesso em: 01/ 08/2006.

AIKAWA, Romy. Faca de dois gumes. Folha de S. Paulo, São Paulo, 30 set. 2003. Caderno Sinapse.

ALPERSTEDT, Cristiane. Universidades corporativas: definição proposta. Univesia, 2003. Disponível em <http://www.universia.com.br/ html/materia/materia_bdca.html> Acesso em: 27/07/2006.

ALVES, Giovanni. Toyotismo e neocorporativismo no sindicalismo do século XXI. São Paulo: [s.n.], 2001.

ANDERSON, Perry. Balanço do Neoliberalismo. In: SADER, Emir; GENTILI, Pablo. Pós-neoliberalismo. Rio de Janeiro: Paz e Terra, 1995

ANTUNES, Ricardo. Adeus ao trabalho? Ensaio sobre as metamorfoses e a centralidade do mundo do trabalho. 6.ed. São Paulo: Cortez, 1999.

BRETON, Philippe. A palavra manipulada. Lisboa. Ed. Caminho.2002; CASTANHO, Sérgio. A universidade entre o sim, o não e o talvez. In: VEIGA, I.; CASTANHO, M. (Orgs.). Pedagogia universitária: a aula em foco. Campinas: Papirus, 2000.

CHAUI, Marilena. A universidade em ruínas. In: TRINDADE, Hélgio. (Org.). A universidade em ruínas na república dos professores. Petrópolis: Vozes, 1999.

. Convite a filosofia. São Paulo: Ática. 2003

. O que é ideologia. São Paulo: Brasiliense, 1980.

. Ventos do progresso: a universidade administrada. In: PRADO JÚNIOR, Bento. (Org.). Descaminhos da educação pós-68. São Paulo: Brasiliense, 1980.

DELUIZ, N. A globalização econômica e os desafios à formação profissional. Boletim Técnico do SENAC, Rio de Janeiro, v. 22, n. 2, p. 15-21, maio/ago. 1996. 
DIAS SOBRINHO, José. Concepções de universidade e de avaliação institucional. In: TRINDADE, Hélgio, (Org.). Universidade em ruínas: na república dos professores. Petrópolis: Vozes, 1999.

. Educação superior, globalização e democratização: qual universidade?. Rev. Bras. Educ., Rio de Janeiro, n. 28, 2005. DUBAR, C. A sociologia do trabalho frente à qualificação e a competência. Educação \& Sociedade, Campinas, ano 19, n. 64, p. 87103, set. 1998

EBOLI, M. O desenvolvimento das pessoas e a educação corporativa. In: FLEURY, Maria Tereza Leme Fleury (Org.). As pessoas na organização. São Paulo: Gente, 2002.

FLEURY, Maria T.; FLEURY, A. Estratégias empresariais e formação de competências. Rio de Janeiro: Atlas, 2001.

FREIRE, Paulo, Educação como prática da liberdade. Rio de Janeiro: Paz e Terra, 1967.

HIRATA, H. Da polarização das qualificações ao modelo de competência In: FERRETTI, C. et al. Novas tecnologias, trabalho e educação: um debate multidisciplinar. Petrópolis: Vozes, 1994 HUBERMAN, Leo. História da riqueza do homem. Rio de Janeiro: Zahar, 1972.

MANFREDI, S. M. Trabalho, qualificação e competência profissional: das dimensões conceituais e políticas. Educação \& Sociedade, Campinas, v. 19, n. 64, p. 13-49, set. 1998.

MARX, Karl. O capital. São Paulo: Nova Cultural, 1983.

MENEGHEL, Stela M. A crise da universidade moderna no Brasil. 2001. Tese (Doutorado) - Universidade Estadual de Campinas, Campinas, 2001.

POPPER, Karl; CONDRY, John. Televisão: um perigo para a democracia? Lisboa: Gradiva, 1995.

RAMOS, M. N. A pedagogia das competências: autonomia ou adaptação? São Paulo: Cortez, 2001.

ROCHA, Ruth. Minidicionário. São Paulo: Scipione, 1996

SANTOMÉ, Jurjo Torres. A educação em tempos de neoliberalismo. Porto Alegre: Artmed, 2003.

SANTOS, Boaventura de Souza. A universidade no século XXI: para uma reforma democrática e emancipatória da universidade. São Paulo: Cortez, 2004 
SANTOS, Milton. Grandes empresas dominam a política. Folha de $\mathbf{S}$. Paulo, São Paulo, 8 jan. 2001.

SAPERAS, Enric. Os efeitos cognitivos da comunicação de massa.

Porto, Portugal: Asa, 1993

SILVA, Marco Wandercil. Universidade corporativa: uma avaliação no contexto do ensino superior no Brasil. 2005. 134p. Dissertação (Mestrado) - Pontifícia Universidade Católica de Campinas, Campinas, 2005.

TRINDADE, Hélgio. Saber e poder: os dilemas da universidade brasileira. Estudos Avançados, São Paulo, v. 14, n. 40, set. 2000.

Endereço dos autores:

Newton César Balzan

End.: Av. Princesa D'Oeste, 1.144 ap. 31, J.d Guarani - Campinas / SP CEP: 13095-010

Marco Wandercil da Silva

End.: Rua Mantovanis, 248, J.d João Aldo Nassif, Jaguariúna / SP - CEP: 13820-000 